\title{
The 6-item Female Sexual Function Index (FSFI-6): factor structure, reliability, and demographic correlates among infertile women in Iran
}

\author{
Saman Maroufizadeh ${ }^{1}$, Hedyeh Riazi ${ }^{2}$, Hajar Lotfollahi ${ }^{2}$, Reza Omani-Samani ${ }^{3}$ and Payam Amini ${ }^{*}$
}

\begin{abstract}
Background: The 6-item Female Sexual Function Index (FSFI) is a short form of the original 19-item FSFI that measures sexual function in women. The aim of this study was to examine the factor structure and reliability of the FSFI-6 and to determine the demographic correlates of sexual dysfunction among infertile women in Iran.

Results: In total, 250 infertile women participated in this study. The mean total FSFI-6 score was $20.71 \pm 5.09$. Internal consistency of the FSFI-6 was high (Cronbach's alpha $=0.856$ ). All inter-item correlations and item-total correlations were in acceptable range. The results of confirmatory factor analysis provided support for a unidimensional model of the FSFI-6. Among demographic and infertility variables, higher women's age, low education, unwanted marriage, short infertility duration, and low frequency of intercourse were associated with sexual dysfunction.

Conclusions: The FSFI-6 demonstrated sound reliability and validity in this study, supporting its continued use for measuring sexual disfunction among infertile women. Its brevity and comprehensiveness allow a quick assessment both in clinical and research settings.
\end{abstract}

Keywords: Female Sexual Function Index, Sexual Dysfunction, Reliability, Validity, Infertility

\section{Background}

Infertility is defined as "the failure to establish a clinical pregnancy after 12 months of regular, unprotected sexual intercourse or due to an impairment of a person's capacity to reproduce either as an individual or with his/ her partner." [1] and affects $9 \%$ of reproductive-age couples globally [2]. It is a worldwide health problem that is associated with adverse psychological and social consequences [3-7]. Researchers have shown that negative feelings, such as depression, stress, and anxiety, are often mental disorders after experiencing infertility $[4,8,9]$. As most couples consider childbirth as one of the most significant outcomes of sexual intercourse, infertile couples are more prone to experience psychological and

\footnotetext{
* Correspondence: payam.amini87@gmail.com

${ }^{4}$ Department of Biostatistics and Epidemiology, School of Public Health,

Ahvaz Jundishapur University of Medical Sciences, Ahvaz, Iran

Full list of author information is available at the end of the article
}

emotional stress [10]. Infertility profoundly impacts the sexual enjoyment of a couple about scheduling programs for childbirth and fertility interventions [11, 12]. It has been shown that infertile couples have significantly more sexual issues than fertile couples [13]. The belief of sexual orientation is considerably affected by infertilityrelated pressure and depression and the region where infertility has the most adverse effect $[14,15]$.

Sexual behavior is a function of physiologic, anatomic, and psychosocial characteristics of a person [16]. Female sexual dysfunction has been introduced as disorders of sexual functioning, desire, and pain, which is followed by adverse consequences such as negative psychological outcomes [17]. Sexual function is a major element of women's quality of life, which affects several dimensions of peri- and post-menopausal characteristics [18]. Previous studies have shown that on average, $64 \%$ of women suffer from desire difficulty, $35 \%$ of orgasm difficulty, 
$31 \%$ have complications with arousal conditions, and $26 \%$ with sexual pain [19]. Based on a systematic review of literature conducted in Iranian infertile women, the overall prevalence of female sexual dysfunction was $64.3 \%$ [20]. It has been argued that female sexual function is associated with age, body physics, hormonal condition, neurologic and vascular processes, and psychological health items [21].

A variety of instruments have been developed to measure female sexual function. Among these instruments, the 19-item Female Sexual Function Index (FSFI-19) is one of the main instruments for assessing female sexual function [18]. The FSFI-19 is a self-reported instrument, consisting of 6 separate domains of female sexual function, namely desire, arousal, lubrication, orgasm, satisfaction, and pain. This scale has been validated in many languages and widely used in clinical and research settings [22]. Despite being frequently used, psychometrically sound, and clinically interpretable, the FSFI-19 may be too long for use in studies with multiple outcome measures, especially when measuring sexual dysfunction is not a primary aim of a study. Because of this reason, recently, Isidori et al. developed a shorter version of the scale (i.e., FSFI-6) using receiver operating curves [18, 23]. The FSFI- 6 is a brief and easy to use measure containing 6 of the original 19 items. This scale is useful for settings with a limited time frame (e.g., survey research).

The FSFI- 6 has been validated in Italy, the USA, Brazil, Korea, Portugal, and Ecuador, mainly in the general population [18, 23-27]; however, they have not been validated in infertile women. Hence, this study aims to evaluate the validity and reliability of the FSFI- 6 among a sample of women with infertility. A secondary aim was to determine the demographic correlates of sexual dysfunction among infertile women in Iran.

\section{Methods}

\section{Participants and study design}

The sample of this cross-sectional study consisted of infertile women referring to infertility treatment center of Royan Institute, Tehran, Iran. The data were collected between January and April 2017. The sample size was determined using the rule of thumb recommended by Guilford [28] and Cattell [29] for factor analysis studies. They offered researchers to obtain samples of 200 (or 250) subjects whenever possible. To be eligible for this study, subjects had to fulfill the following criteria: (1) women with infertility problem, (2) age between 18 and 45 years, and (3) ability to read and write in Persian. Participants were asked to complete the questionnaire privately and return it. A total of 250 infertile women agreed to take part and fill out the questionnaire completely.
Table 1 Demographic/fertility characteristics of the infertile women $(n=250)$

\begin{tabular}{|c|c|}
\hline & Mean \pm SD or $n(\%)$ \\
\hline Age (years) & $29.74 \pm 5.29$ \\
\hline \multicolumn{2}{|l|}{ Education } \\
\hline Primary & $1(0.4)$ \\
\hline Secondary & $36(14.4)$ \\
\hline Diploma & $91(36.4)$ \\
\hline Associate & $29(11.6)$ \\
\hline Bachelor & $68(27.2)$ \\
\hline Master/Doctoral & $25(10.0)$ \\
\hline Husband's age (years) & $33.99 \pm 5.29$ \\
\hline \multicolumn{2}{|l|}{ Husband's education } \\
\hline Primary & $13(5.2)$ \\
\hline Secondary & $43(17.2)$ \\
\hline Diploma & $91(36.4)$ \\
\hline Associate & $22(8.8)$ \\
\hline Bachelor & $53(21.2)$ \\
\hline Master/Doctoral & $28(11.2)$ \\
\hline \multicolumn{2}{|l|}{ Occupation } \\
\hline Unemployed & $197(78.8)$ \\
\hline Employed & $53(21.2)$ \\
\hline BMI $\left(\mathrm{kg} / \mathrm{m}^{2}\right)$ & $25.68 \pm 3.74$ \\
\hline Duration of marriage (years) & $7.12 \pm 3.91$ \\
\hline \multicolumn{2}{|l|}{ Type of marriage } \\
\hline Wanted & $242(96.8)$ \\
\hline Unwanted & $8(3.2)$ \\
\hline Duration of infertility (years) & $5.54 \pm 3.87$ \\
\hline \multicolumn{2}{|l|}{ Cause of infertility } \\
\hline Female factor & $54(21.6)$ \\
\hline Other factors & $196(78.4)$ \\
\hline \multicolumn{2}{|l|}{ Private room } \\
\hline No & $28(11.2)$ \\
\hline Yes & $222(88.8)$ \\
\hline \multicolumn{2}{|l|}{ Living with others } \\
\hline No & $218(87.2)$ \\
\hline Yes & $32(12.8)$ \\
\hline Frequency of intercourse per month & $8.56 \pm 4.50$ \\
\hline \multicolumn{2}{|l|}{ Masturbation } \\
\hline No & $212(84.8)$ \\
\hline Yes & $38(15.2)$ \\
\hline
\end{tabular}

$S D$ standard deviation

\section{Questionnaires}

\section{Demographic variables}

Participants provided demographic/infertility information including age, education, husband's age, husband's education, occupation, type of marriage, body mass index (BMI), cause of infertility, infertility duration, frequency of intercourse per month, frequency of 
Table 2 Item wording and descriptive statistics and internal consistency of the FSFI-6

\begin{tabular}{|c|c|c|c|c|c|c|}
\hline & Possible range & Mean & SD & Corrected item-total correlation & Alpha if item deleted & Alpha \\
\hline 1. Desire: level & $1-5$ & 3.09 & 0.65 & 0.423 & 0.867 & \\
\hline 2. Arousal: level & $0-5$ & 3.09 & 1.02 & 0.799 & 0.805 & \\
\hline 3. Lubrication: frequency & $0-5$ & 3.38 & 1.28 & 0.682 & 0.826 & \\
\hline 4. Orgasm: frequency & $0-5$ & 3.45 & 1.31 & 0.778 & 0.804 & \\
\hline 5. Satisfaction: with overall sex life & $1-5$ & 3.96 & 1.05 & 0.697 & 0.823 & \\
\hline 6. Pain: frequency during vaginal penetration & $0-5$ & 3.74 & 1.23 & 0.542 & 0.853 & \\
\hline FSFI-6 total score & $2-30$ & 20.71 & 5.09 & & & 0.856 \\
\hline
\end{tabular}

SD standard deviation

masturbation per month, and having private room, life in home with other family members or people.

\section{The 6-item Female Sexual Function Index (FSFI-6)}

The FSFI-6 is a 6-item, brief, and self-administered instrument derived from the original 19-item FSFI that measures female sexual function [23]. It comprises six domains: desire, arousal, lubrication, orgasm, satisfaction, and pain. Desire and satisfaction items are rated on a 5-point Likert scale, ranging from 1 to 5 , and the other items are rated on a 6-point Likert scale, ranging from 0 to 5 . Total scores range from 2 to 30 , with lower scores indicating worse sexual functioning.

\section{Statistical analysis}

The factor structure of the FSFI- 6 was examined with confirmatory factor analysis (CFA) using maximum likelihood estimation. Overall model fit was examined using multiple fit criteria, as suggested in the literature. Specifically, six goodness-of-fit indices were used, including chi-square/degree of freedom $\left(\chi^{2} / \mathrm{df}\right)$, comparative fit index (CFI), normalized fit index (NFI), incremental fit index (IFI), root mean square error of approximation (RMSEA), and standardized root mean square residual (SRMR). Values of $\chi^{2} / \mathrm{df}<$ 3 , CFI, NFI, and IFI > 0.95, and RMSEA and SRMR $<0.08$ are indicative of a good fit with the data [3033]. To evaluate the internal consistency of the FSFI6. Cronbach's alpha, inter-item correlation, and corrected-item total correlation were calculated. Cronbach's alpha value of 0.7 or greater indicates that the internal consistency is satisfactory [34]. Inter-item correlations examine the extent to which scores on one item are related to scores on all other items in a scale. The corrected item-total correlation is the correlation between each item and the total scale score based on the other items. Smaller values (i.e., less than 0.3 ) indicate that the given item is not well correlated with the others [35]. To examine the relationship of female sexual function (i.e., FSFI-6 scores) with demographic/infertility characteristics, stepwise backward regression analysis was done. Goodness of fit of the regression model was evaluated using the coefficient of determination $\left(R^{2}\right)$, which is the proportion of variation in the dependent variable explained by the regression model. Data analyses were carried

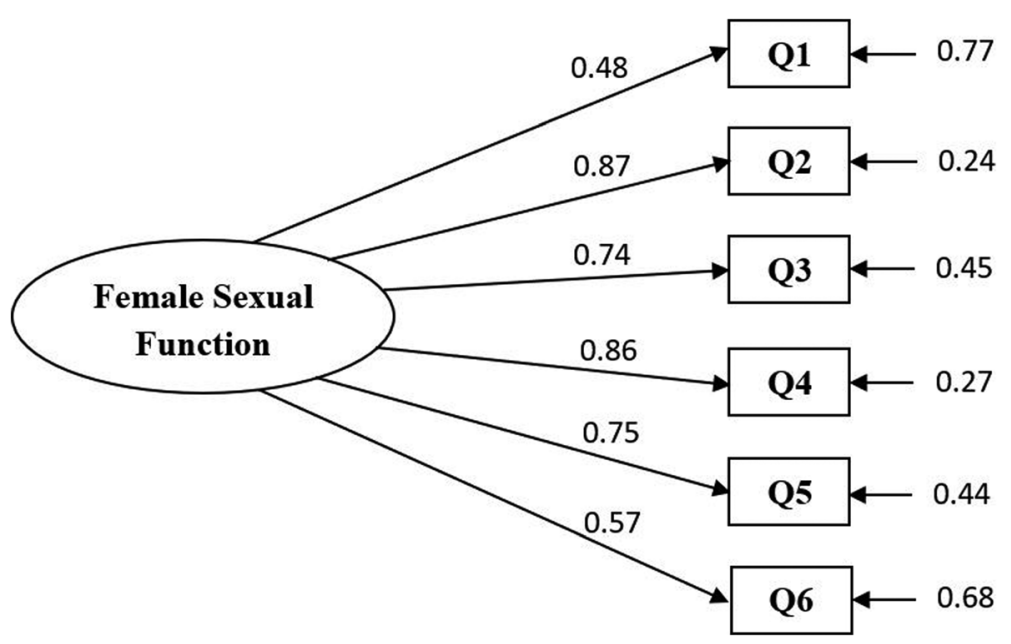

Fig. 1 The unidimensional factor model of FSFI-6 in a sample of infertile women 
out using SPSS for Windows, version 16.0 (SPSS Inc., Chicago, IL, USA) and LISREL 8.80 (Scientific Software International, Inc., Lincolnwood, IL, USA).

\section{Results}

\section{Participant characteristics}

Table 1 outlines the demographic characteristics of infertile women. The mean age of the participants was $29.74 \pm 5.29$ years. The majority of participants were unemployed (78.8\%), had a private room at home (88.8\%), and did not live with others (87.2\%). The mean BMI was $25.68 \pm 3.74 \mathrm{~kg} / \mathrm{m}^{2}$.

\section{Descriptive statistics and internal consistency of the FSFI-}

6

The descriptive statistics and internal consistency of the FSFI-6 are displayed in Table 2. The mean FSFI-6 total score was $20.71 \pm 5.09$. The FSFI- 6 showed high internal consistency with Cronbach's alpha coefficient of 0.856 . As seen in Table 2, Cronbach's alpha did not considerably increase as a consequence of an item deletion. The corrected item-total correlations and the inter-item correlations ranged $0.423-0.799$ and $0.216-0.738$, respectively.

\section{Factor structure of the FSFI-6}

To examine the factor structure of the FSFI- 6 , the CFA was carried out. The result of CFA confirmed the unidimensional factor structure of the FSFI-6 $\left(\chi^{2} / \mathrm{df}=2.96\right.$; $\mathrm{CFI}=0.98 ; \mathrm{NFI}=0.97 ; \mathrm{IFI}=0.98 ; \mathrm{RMSEA}=0.089$ and SRMR $=0.035)$. As can be seen in Fig. 1, all factor loadings were significant and greater than 0.50 , except for item 1.

\section{Demographic correlates of the FSFI-6 scores}

Stepwise backward regression analysis was used to investigate the relationships between FSFI- 6 scores and demographic/infertility characteristics. According to the results (see Table 3$)$, higher women's age $(b=-0.206, P$ $=0.004)$, low education $(b=0.718, P=0.012)$, unwanted marriage $(b=-4.765, P=0.008)$, short infertility duration $(b=0.200, P=0.037)$, and low frequency of intercourse $(b=0.250, P<0.001)$ were associated with sexual dysfunction. The model $R^{2}$ when demographics and infertility variables were in the model was equal to 0.12 , suggesting that these variables explained $12.0 \%$ of the variance in FSFI-6 scores. Other variables were not related to FSFI-6 scores.

\section{Discussion}

To our knowledge, this is the first study to evaluate the reliability and validity of the FSFI- 6 in a sample of infertile women. The FSFI-6 is a quick and easy to administer instrument and considered a parsimonious alternative to
Table 3 Relationship of FSFI-6 scores with demographic and infertility variables in infertile women using stepwise backward regression analysis

\begin{tabular}{lllll}
\hline Variable & $b$ & SE & $\beta$ & $P$ \\
\hline Age & -0.206 & 0.070 & -0.214 & 0.004 \\
Education & 0.718 & 0.285 & 0.179 & 0.012 \\
Unwanted marriage & -4.765 & 1.779 & -0.165 & 0.008 \\
Infertility duration & 0.200 & 0.095 & 0.152 & 0.037 \\
Frequency of intercourse & 0.250 & 0.070 & 0.221 & $<0.001$ \\
\hline
\end{tabular}

$b$ unstandardized coefficient, SE standard error, $\beta$ standardized coefficient

the long form of the FSFI. This scale incorporates one item of each of the six domains of the original FSFI, thus allowing rapid screening of these domains.

The FSFI-6 demonstrated satisfactory internal consistency $(\alpha=0.856)$, and the alpha value did not increase substantially when each item was removed. All inter-item correlations and corrected item-total correlations were also within an acceptable range, confirming good internal consistency. This result is consistent with what was reported in the original study $(\alpha=0.789)$ [23], Korean version $(\alpha=0.888)$ [24], middle-aged Brazilian and Portuguese women $(\alpha=0.840$ and $\alpha=0.890$, respectively) $[25,26]$, and Ecuadorian sample $(\alpha=0.91)$ [36].

The findings of CFA provided support for a unidimensional model of FSFI-6. This finding was also reported in two studies conducted in middle-aged Brazilian and Portuguese women $[25,26]$.

Among demographic and fertility factors, higher women's age, low education, unwanted marriage, short infertility duration, and low frequency of intercourse were associated with sexual dysfunction. In a study conducted among mid-aged Ecuadorian women [36], total FSFI-6 scores positively correlated with coital frequency and female and partner educational level and inversely with female age, waist circumference, hot flush intensity, and partner age. In another study performed among mid-aged sexually active Spanish women, total FSFI-6 scores displayed a positive correlation with female and partner education and negative correlation with female age [36]. Contrary to our findings, Iris et al. [15] showed that a long infertility duration was associated with the likelihood of sexual dysfunction in women.

In the present study, several limitations should be pointed out. First, the sample was drawn from a single center and included only infertile women in Iran. Therefore, the generalizability of the present findings may be limited. Second, because of the cross-sectional nature of this study, causal inference between FSFI- 6 scores and demographic characteristics of women cannot be drawn. Third, the test-retest reliability of the FSFI- 6 was not assessed in this study. Fourth, although the cutoff point is available for the original, Korean, and Ecuadorian 
versions, further research is required to determine the cutoff point for the Iranian population.

\section{Conclusions}

In sum, the FSFI- 6 is a reliable and valid instrument that can be used to assess female sexual function in infertile women. Its brevity and comprehensiveness allow a quick assessment both in clinical and research settings.

\section{Abbreviations}

CFA: Confirmatory factor analysis; CFI: Comparative fit index; FSFI-6: 6-Item Female Sexual Function Index; IFI: Incremental fit index; NFI: Normalized fit index; RMSEA: Root mean square error of approximation; SRMR: Standardized root mean square residual

\section{Acknowledgements}

We thank the infertile women who participated in this research and the Royan Institute, Tehran, Iran, for cooperation in data acquisition.

\section{Authors' contributions}

SM contributed to the conception and design, analysis and interpretation of the data, and drafting of the article. PA contributed to the conception and design, interpretation of the data, and drafting of the article. HR, ROS, and $\mathrm{HL}$ contributed to the conception and design, collection and assembly of data, and drafting of the article. All authors approved the final version of the article for submission.

\section{Funding}

This research received no specific grant from any funding agency in the public, commercial, or not-for-profit sectors.

\section{Availability of data and materials}

The datasets used and/or analyzed during the current study are available from the corresponding author on reasonable request.

\section{Ethics approval and consent to participate}

The Ethics Committee of Royan Institute, Tehran, Iran, approved this study (registration number: IR.ACECR.ROYAN.REC.1395.140). Agreement to participate and written informed consent were obtained from all infertile women before data collection.

\section{Consent for publication}

Not applicable.

\section{Competing interests}

The authors declare that they have no competing interests.

\section{Author details}

${ }^{1}$ School of Nursing and Midwifery, Guilan University of Medical Sciences, Rasht, Iran. ${ }^{2}$ Department of Midwifery and Reproductive Health, School of Nursing and Midwifery, Shahid Beheshti University of Medical Sciences, Tehran, Iran. ${ }^{3}$ Department of Medical Ethics and Law, Reproductive Biomedicine Research Center, Royan Institute for Reproductive Biomedicine, ACECR, Tehran, Iran. ${ }^{4}$ Department of Biostatistics and Epidemiology, School of Public Health, Ahvaz Jundishapur University of Medical Sciences, Ahvaz, Iran.

Received: 4 July 2019 Accepted: 11 November 2019

Published online: 11 December 2019

\section{References}

1. Zegers-Hochschild F, Adamson G, Dyer S, Racowsky C, de Mouzon J, Sokol R, Rienzi L, Sunde A, Schmidt L, Cooke I et al (2017) The International Glossary on Infertility and Fertility Care, 2017. Fertil Steril 108(3):393-406

2. Boivin J, Bunting L, Collins JA, Nygren KG (2007) International estimates of infertility prevalence and treatment-seeking: potential need and demand for infertility medical care. Hum Reprod 22(6):1506-1512

3. Omani-Samani R, Ghaheri A, Navid B, Sepidarkish M, Maroufizadeh S (2018) Prevalence of generalized anxiety disorder and its related factors among infertile patients in Iran: a cross-sectional study. Health Qual Life Outcomes 16(1):129

4. Maroufizadeh S, Ghaheri A, Almasi-Hashiani A, Mohammadi M, Navid B, Ezabadi Z, Samani RO (2018) The prevalence of anxiety and depression among people with infertility referring to Royan Institute in Tehran, Iran: a cross-sectional questionnaire study. Middle East Fertil Soc J 23(2):103-106

5. Omani-Samani R, Maroufizadeh S, Almasi-Hashiani A, Amini P (2018) Prevalence of depression and its determinant factors among infertile patients in Iran based on the PHQ-9. Middle East Fertil Soc J 23(4):460-463

6. Omani-Samani R, Maroufizadeh S, Ghaheri A, Amini P, Navid B (2017) Reliability and validity of the Kansas Marital Satisfaction Scale (KMSS) in infertile people. Middle East Fertil Soc J 23(2):154-157

7. Maroufizadeh S, Omani-Samani R, Bagheri-Lankarani N, Almasi-Hashiani A, Amini P (2018) Factors associated with poor well-being of infertile people: a cross-sectional study. Middle East Fertil Soc J 23(4):468-470

8. Kim M, Nam H, Youn M (2016) Infertility stress, depression, and resilience in women with infertility treatments. J Korean Public Health Nurs 30(1):93-104

9. Maroufizadeh S, Karimi E, Vesali S, Omani Samani R (2015) Anxiety and depression after failure of assisted reproductive treatment among patients experiencing infertility. Int J Gynaecol Obstet 130(3):253-256

10. Sargolzaee MR, Moharreri F, Arshadi HR, Javadi K, Karimi S, Fayyazi-bordbar MR (2001) Psychosexual and depression disorders in infertile female referring to Mashhad Infertility Treatment Center. J Reprod Infertil:2(4)

11. Higgins JA, Wang Y (2015) Which young adults are most likely to use withdrawal? The importance of pregnancy attitudes and sexual pleasure. Contraception 91(4):320-327

12. Piva I, Lo Monte G, Graziano A, Marci R (2014) A literature review on the relationship between infertility and sexual dysfunction: does fun end with baby making? Eur J Contracept Reprod Health Care 19(4):231-237

13. Tayebi N, Ardakani SMY (2007) The prevalence of sexual dysfunctions in infertile women. Middle East Fertil Soc J 12(3):184-187

14. Millheiser LS, Helmer AE, Quintero RB, Westphal LM, Milki AA, Lathi RB (2010) Is infertility a risk factor for female sexual dysfunction? A case-control study. Fertil Steril 94(6):2022-2025

15. Iris A, Kirmizi DA, Taner CE (2013) Effects of infertility and infertility duration on female sexual functions. Arch Gynecol Obstet 287(4):809-812

16. Çayan S, Akbay E, Bozlu M, Canpolat B, Acar D, Ulusoy E (2004) The prevalence of female sexual dysfunction and potential risk factors that may impair sexual function in Turkish women. Urol Int 72(1):52-57

17. Munarriz R, Kim NN, Goldstein I, Traish AM (2002) Biology of female sexual function. Urol Clin North Am 29(3):685-693

18. Carpenter JS, Jones SM, Studts CR, Heiman JR, Reed SD, Newton KM, Guthrie KA, Larson JC, Cohen LS, Freeman EW (2016) Female Sexual Function Index short version: a MsFLASH item response analysis. Arch Sex Behav 45(8):1897-1905

19. Hayes RD, Bennett CM, Fairley CK, Dennerstein L (2011) Epidemiology: what can prevalence studies tell us about female sexual difficulty and dysfunction? J Sex Med 3(4):589-595

20. Omani-Samani R, Amini P, Navid B, Sepidarkish M, Maroufizadeh S, AlmasiHashemi A (2019) Prevalence of sexual dysfunction among infertile women in Iran: a systematic review and meta-analysis. Int J Fertil Steril 12(4):278-283

21. Stuckey BG (2008) Female sexual function and dysfunction in the reproductive years: the influence of endogenous and exogenous sex hormones. J Sex Med 5(10):2282-2290

22. Neijenhuijs Kl, Hooghiemstra N, Holtmaat K, Aaronson NK, Groenvold M, Holzner B, Terwee CB, Cuijpers P, Verdonck-de Leeuw IM (2019) The Female Sexual Function Index (FSFI) - a systematic review of measurement properties. J Sex Med 16(5):640-660

23. Isidori A, Pozza C, Esposito K, Ciotola M, Giugliano D, Morano S, Lenzi A, Jannini E (2010) Development and validation of a 6-item version of the Female Sexual Function Index (FSFI) as a diagnostic tool for female sexual dysfunction. J Sex Med 7(3):1139-1146

24. Lee $Y$, Lim MC, Joo J, Park K, Lee S, Seo S, Lee DO, Park S-Y (2014) Development and validation of the Korean version of the Female Sexual Function Index-6 (FSFI-6 K). Yonsei Med J 55(5):1442-1446

25. Dall'Agno ML, Ferreira CF, Ferreira FV, Pérez-López FR, Wender MCO (2019) Validation of the Six-item Female Sexual Function Index in middle-aged Brazilian women. Rev Bras Ginecol Obstet 41(7):432-439

26. Pimenta F, Albergaria R, Gomes M, Maroco J, Leal I, Chedraui P, Pérez-López FR (2017) Preliminary validating analysis of the Portuguese language 6-item Female Sexual Function Index (FSFI-6). Maturitas 100:143-144 
27. Armeni A, Salazar-Pousada D, Andrade-Ponce SS, Tupacyupanqui-Mera JC, Pérez-López FR, Chedraui P (2017) Reliability and validity of FSFl-6 in midaged Ecuadorian women. Maturitas 103:93

28. Guilford JP (1954) Psychometric methods. McGraw Hill, New York

29. Cattell R (1978) Use of factor analysis in behavioral and life sciences. Plenum Press, New York

30. Bentler PM (1990) Comparative fit indexes in structural models. Psychol Bull 107(2):238-246

31. Byrne BM (1994) Structural equation modeling with EQS and EQS/Windows: basic concepts, applications, and programming. Sage Publications, Thousand Oaks

32. McDonald RP, Ho M-HR (2002) Principles and practice in reporting structural equation analyses. Psychol Methods 7(1):64-82

33. Kline RB (2015) Principles and practice of structural equation modeling. Guilford Publications, New York

34. Nunally JC, Bernstein IH (1994) Psychometric theory, 3rd edn. McGraw-Hill, New York

35. Kline P (2013) Handbook of psychological testing. Routledge, London

36. Chedraui P, Pérez-López FR, Sánchez H, Aguirre W, Martínez N, Miranda O, Plaza MS, Schwager G, Narváez J, Quintero JC (2012) Assessment of sexual function of mid-aged Ecuadorian women with the 6-item Female Sexual Function Index. Maturitas 71(4):407-412

\section{Publisher's Note}

Springer Nature remains neutral with regard to jurisdictional claims in published maps and institutional affiliations.

\section{Submit your manuscript to a SpringerOpen ${ }^{\circ}$ journal and benefit from:}

- Convenient online submission

- Rigorous peer review

- Open access: articles freely available online

- High visibility within the field

- Retaining the copyright to your article 